JURNAL RAB CONTRUCTION RESEARCH
UNIVERSITAS
ABDURRAB

\title{
PERENCANAAN ULANG SALURAN DRAINASE JALAN HARAPAN KECAMATAN RUMBAI PESISIR KOTA PEKANBARU
}

\author{
Miftahul Jannah ${ }^{1}$, Virgo Trisep Haris ${ }^{2}$, Muthia Anggraini ${ }^{3 *}$ \\ Program Studi Teknik Sipil, Fakultas Teknik, Universitas Lancang Kuning \\ Jl. Yos Sudarso km 8 Rumbai, Pekanbaru Indonesia (0761) 52324 \\ muthia@unilak.co.id
}

\begin{abstract}
Info Artikel
Abstrak

Sejarah Artikel:

Fungsi drainase adalah untuk mengalirkan air agar tidak terjadi genangan di

Diterima : Oktober 2021

Disetujui : Desember 2021

Dipublikasikan: Des 2021 permukaan jalan yang dapat mengakibatkan terganggunya aktifitas masyarakat dan rusaknya kontruksi jalan. Di Jalan Harapan Kecamatan Rumbai Pesisir sudah memiliki saluran drainase di bagian kanan dengan tinggi 1,3 $\mathrm{m}$ dan lebar 1,3 $\mathrm{m}$ dan saluran kiri dengan tinggi 1,3 m dan lebar 1,1 m. Namun masih saja sering terjadi genangan air pada permukaan jalan. Kondisi saluran drainase pada jalan harapan mengalami cekungan sehingga menyebabkan tergenangnya air pada daerah tersebut. Tujuan penelitian ini untuk melakukan perencaan ulang guna memperbaiki kondisi saluran drainase yang ada sehingga dapat mengalirkan air. Metode yang

Keywords:

Debit; Dimensi;

Drainase; Ekevasi digunakan ialah metode Distribusi Gumbel untuk menghitung frekuensi curah hujan, SNI 03-3424-1994 untuk menghitung intesitas curah hujan, dan metode manning untuk menghitung kecepatan aliran. Dari hasil perencanaan didapat dimensi tinggi 1,75 $\mathrm{m}$ dan lebar 1,5 $\mathrm{m}$ dengan elevasi hulu 99,013 dan elevasi hilir 98,8108 untuk saluran kanan dan saluran kiri tinggi 1,45 m dan lebar 1,2 $\mathrm{m}$ dengan elevasi hulu 98,429 dan elevasi hilir 98,227 untuk saluran kiri. Kesimpulannya dimensi saluran kanan adalah tinggi 1,75 $\mathrm{m}$ dan lebar 1,5 m pada saluran kiri tinggi $1,45 \mathrm{~m}$ dan lebar $1,2 \mathrm{~m}$.
\end{abstract}

Kata Kunci: Debit, Dimensi, Drainase, Elevasi

\begin{abstract}
The function of drainage is to drain water so that there is no puddle on the road surface which can disrupt community activities and damage to road construction. On Jalan Harapan, the Rumbai Pesisir sub-district already has a drainage channel on the right with a height of $1.3 \mathrm{~m}$ and $a$ width of $1.3 \mathrm{~m}$ and a left channel with $a$ height of $1.3 \mathrm{~m}$ and $a$ width of $1.1 \mathrm{~m}$. However, there are still frequent puddles of water on the road surface. The condition of the drainage channel on the hope road is hollow, causing waterlogging in the area. The purpose of this research is to do a re-planning to improve the condition of the existing drainage channel so that it can drain water. The method used is the Gumbel distribution method to calculate the frequency of rainfall, SNI 03-3424-1994 to calculate the intensity of rainfall and the manning method to calculate the flow velocity. From the planning results, the
\end{abstract}


dimensions are $1.75 \mathrm{~m}$ high and $1.5 \mathrm{~m}$ wide with an upstream elevation of 99,013 and a downstream elevation of 98.8108 for the right channel and the left channel with a height of $1.45 \mathrm{~m}$ and $a$ width of $1.2 \mathrm{~m}$ with an upstream elevation of 98.429 and an elevation of 98.429. downstream 98,227 for the left channel. In conclusion, the dimensions of the right channel are $1.75 \mathrm{~m}$ high and $1.5 \mathrm{~m}$ wide, the left channel is $1.45 \mathrm{~m}$ high and $1.2 \mathrm{~m}$ wide.

\begin{tabular}{lr} 
& C 2021 Universitas Abdurrab \\
\hline Alamat korespondensi: & ISSN 2527-7073 \\
J1. Yos Sudarso km 8, Rumbai Pekanbaru Indonesia & \\
E-mail: $\underline{\text { muthia@ } \text { unilak.com }}$ &
\end{tabular}

\section{PENDAHULUAN}

Pada daerah perkotaan, sistem drainase merupakan infrastruktur yang sangat penting yang fungsinya sebagai aliran air yang asalnya dari kegiatan rumah tangga ataupun air yang berasal dari air hujan [1]. Drainase nerasal dari kata drainage dengan arti mengalirkan ataupun mengeringkan. Sistem drainase terbagi menjadi 2 macam, yaitu drainase terbuka dan drainase tertutup [2].

Jalan Harapan Kecamatan Rumbai Pesisir Kota Pekanbaru memiliki panjang 1.800 meter, dengan titik yang sering mengalami genangan berada pada Sta $0+68,7$ hingga Sta 0+343,7. Drainase pada Jalan Harapan Kecamatan Rumbai Pesisir Kota Pekanbaru sering mengalami genangan ketika terjadi hujan. Kondisi tersebut disebabkan oleh kondisi lapangan pada daerah yang mengalami genangan berada pada daerah cekungan sehingga menyebabkan terganggunya aktifitas masyarakat dan rusaknya permukaan jalan. Sehingga perlu adanya perencanaan ulang kondisi saluran sehingga dapat mengalirkan air sesuai dengan fungsinya.

\section{TINJAUAN PUSTAKA}

\section{Pengertian Drainase}

Drainase atau drainage yang memiliki arti mengalirkan atau mengalihkan air adalah suatu usaha yang di gunakan untuk mengalirkan atau mengalihkan air permukaan ataupun air di bawah permukaan tanah [3].

- Drainase perkotaan

Sistem drainase perkotaan adalah sistim pengalihan dan mengeringkan air yang mengalir di wilayah perkotaan [4]. Secara umum pengertian drainase adalah suatu Ilmu Pengetahuan yang mempelajari usaha untuk mengalirkan air yang fungsinya pemanfaatan tertentu [5].

- Jenis drainase

Drainase dapat dibedakan menjadi beberapa aspek, meliputi : drainase berdasarkan sejarah terbentuknya, yang terbagi menjadi drainase ilmiah dan drainase buatan. Drainase berdasarkan letak saluran, yang terbagi menjadi drainase muka tanah dan 
drainase bawah tanah. Drainase menurut fungsinya, yang terbagi menjadi single purpose dan multy purpose. Dan drainase menurut kontruksinya yang terbagi menjadi saluran terbuka dan saluran tertutup [4].

\section{Hidrologi}

- Siklus hidroligi

Siklus dari hidrologi merupakan proses yang berawal dari penguapan levaporasi, yang selanjutnya terjadi kondensasi dari awan yang merupakan hasil dari evaporasi, awan terus berproses menjadi hujan yang jatuh ke tanah, kemudian air hujan yang jatuh dapat dibagi menjadi dua yaitu, run off dan juga ada yang meresap/ infiltrasi kedalam lapisan tanah, selanjutnya air akan mengalir ke muara seperti laut, danau, sungai, dan setelah itu kembali lagi keawal proses terjadinya penguapan [4].

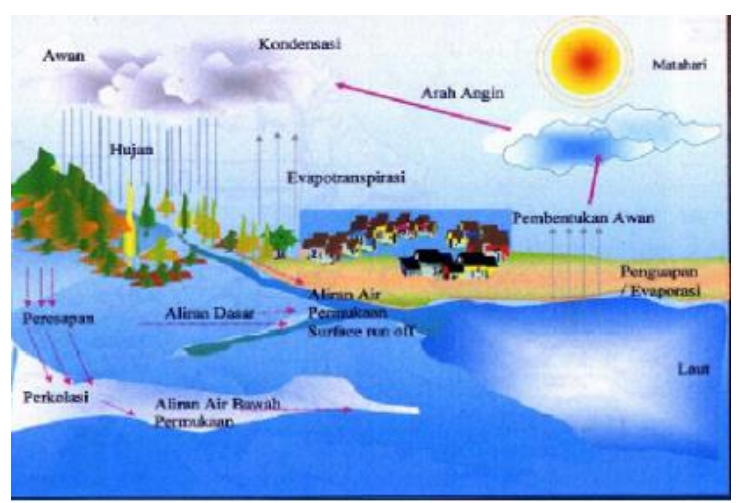

Gambar 1 Proses Terjadinya Husjan (Hasmar, 2012)

- Karakteristik hujan

Setiap daerah memiliki karakteristik hujan yang berbeda-beda, bergantung kepada kondisi daerah tersebut. Karakteristik hujan menurut meliputi durasi hujan, intensitas hujan, lengkung hujan, dan waktu konsentrasi [4].

- Data hujann

Data hujan yaitu suatu bagian yang sangat vital dalam menganalisis hidroligi dalam merencanakan debit [6].

\section{Analisis frekuensi curah hujan}

Analaisi curah hujan sangat diperlukan dalam menentukan curah hujan dalam periode $\mathrm{T}$ tahun. Analisis frekuensi curah hujan yaitu proses dari analisis hujan atau debit berdasarkan sifat statistik suatu data ada sehingga mendapatkan nilai probabilitas besaran hujan dimasa mendatang [7]. Perhitungan dari frekuensi curah hujan dapat dihitung dengan menggunakan Distribusi Gumbel [8]:

$$
\begin{aligned}
& \mathrm{Sx}=\sqrt{\frac{\sum(x i-x)^{2}}{(n-1)}} \\
& \mathrm{XT}=\mathrm{X}+\frac{S x}{S n}\left(Y_{T}-Y_{n}\right)
\end{aligned}
$$


Keterangan :

Sx $=$ Standar Deviasi

$\mathrm{Xi}=$ Data curah hujan rata-rata $(\mathrm{mm})$

$\mathrm{Xr}=$ Rata-rata Curah Hujan Maksimum

$\mathrm{N}=$ Jumlah Data

$\mathrm{Y}_{\mathrm{T}}=$ Reduced variated

$\mathrm{Y}_{\mathrm{n}}=$ Reduced mean (rata-rata dikurangi)

$\mathrm{S}_{\mathrm{n}}=$ Reduced standart deviation

$\mathrm{Xt}$ = Rencana Hujan Tahunan

\section{Intesitas curah hujan}

Intesitas curah hujan berguna dalam penentuan debit banjir dan run off. Menghitung intesitas curah hujan disini menggunakan metode [9], adalah:

$\mathrm{XT}=X+\frac{S x}{S n}(Y t-Y n)$

$\mathrm{I}=\frac{90 \% \times X T}{4} \mathrm{~mm} / \mathrm{jam}$

Keterangan :

I = Intensitas curah hujan ( $\mathrm{mm} / \mathrm{jam})$

$\mathrm{XT}=$ Besarnya curah hujan untuk periode ulang $\mathrm{T}$ tahun $(\mathrm{mm})$

$\mathrm{Sx}=$ Standar deviasi hujan rata-rata

$\mathrm{Sn}=$ Standar deviasi merupakan fungsi dari $\mathrm{n}$ tahun

$\mathrm{Yt}=$ Variasi yang merupakan fungsi dari periode ulang

$\mathrm{Yn}=$ Nilai yang tergantung dari $\mathrm{n}$ tahun

\section{Catchment area}

Catchment areal daerah tangkapan yaitu luas daerah yang berfungsi untuk mengalirkan air ke saluran drainase. Dalam [9] panjang catchment area tergantung pada keadaan daerah setempat dan panjang maksimum yaitu $100 \mathrm{~m}$.

\section{Koefisien pengaliran}

Perhitungan koefisien pengaliran berfungsi sebagai informasi untuk mengetahui banyaknya debit aliran air yang akan dilewati saluran drainase tersebut [10].

$C=\frac{C 1 . A 1+C 2 . A 2+C 3 . A 3+C 4 . A 4}{A 1+A 2+A 3+A 4}$

Keterangan :

$\mathrm{C}$

$=$ Koefisien pengaliran gabungan

$\mathrm{C} 1, \mathrm{C} 2, \mathrm{C} 3$, dan $\mathrm{C} 4$

= Koefisien pengaliran yang sesuai dengan tipe kondisi permukaan 
$\mathrm{A} 1, \mathrm{~A} 2, \mathrm{~A} 3$, dan $\mathrm{A} 4=$ Luas daerah pengaliran yang di perhitungkan sesuai kondisi permukaan.

\section{Analisa debit curah hujan}

Karena wilayah aliran tidak begitu luas untuk curah hujan yang dianggap seragam, perhitungan analisa debit curah hujan bisa dilakukan menggunakan metode rasional [7].

Qch $=0,278 \times$ C x I x A

Keterangan :

Qch = Debit curah hujan $\left(\mathrm{m}^{3} /\right.$ detik)

$\mathrm{C}=$ Koefisien aliran permukaaan $(\mathrm{mm})$

I $\quad=$ Intensitas hujan $(\mathrm{mm} / \mathrm{jam})$

A $\quad=$ Luas area $\left(\mathrm{m}^{2}\right)$

$0,278=$ Faktor konversi

\section{Debit kiriman}

Debit kiriman dari drainase cabang (Qk), yang dihitung berdasarkan dimensi dan kecepatan aliran.

\section{Debit banjir rancangan}

Debit banjir rancangan $\left(Q_{r}\right)$ didapat dari debit curah hujan $\left(Q_{c h}\right)$ yang ditambahkan dengan debit air kotor $\left(Q_{a k}\right)$. Debit banjir rancangan nantinya digunakan sebagai perhitungan kapasitas saluran drainase [7].

Qr $=$ Qch + Qak.

Keterangan :

Qr $=$ Debit banjir rancangan $\left(\mathrm{m}^{3} / \mathrm{dt}\right)$

Qch $=$ Debit curah hujan $\left(\mathrm{m}^{3} / \mathrm{dt}\right)$

Qak = Debit air kotor $\left(\mathrm{m}^{3} / \mathrm{dt}\right)$

\section{Perencanaan ulang saluran drainase}

- Perhitungan debit saluran drainase

Debit yang digunakan pada saat perencanaan ulang saluran drainase merupakan debit rencana.

- Perhitungan dimensi saluran drainase

Hasil survey yang dilakukan di lapangan sehingga didapat ukuran jalan dan ukuran eksiting dari drainase, setelah itu melakukan analisis luas dan debit saluran yang ada. Rumus yang digunakan untuk saluran yang berbentuk persegi adalah [11]:

$\mathrm{A}=\mathrm{b} \cdot \mathrm{y}$

$\mathrm{P}=\mathrm{b}+2 . \mathrm{y}$

$\mathrm{T}=\mathrm{b}$ 
$\mathrm{R}=\mathrm{A} / \mathrm{P}$.

$\mathrm{Q}=\mathrm{V} \times \mathrm{A}$

Keterangan :
A $\quad=$ Luasan saluran $\left(\mathrm{m}^{2}\right)$
$\mathrm{P} \quad=$ Keliling basah $(\mathrm{m})$
$\mathrm{B}=$ Lebar saluran $(\mathrm{m})$
$\mathrm{Y} \quad=$ Tinggi saluran $(\mathrm{m})$
$\mathrm{T}=$ Lebar puncak $(\mathrm{m})$
$\mathrm{R}=$ Jari-jari hidrolis $(\mathrm{m})$
$\mathrm{V} \quad=$ Kecepatan aliran $(\mathrm{m} / \mathrm{det})$

Untuk menghitung kecepatan pada aliran dapat digunakan rumus Manning yaitu [1]:

$$
\mathrm{V}=\frac{1}{\mathrm{n}} \times \mathrm{R}^{2 / 3} \times \mathrm{S}^{1 / 2}
$$

$$
\begin{aligned}
& \text { Keterangan: } \\
& \mathrm{V} \quad=\text { Kecepatan aliran (m/det) } \\
& \mathrm{n} \quad=\text { Koefisien kekasaran saluran menurut Manning } \\
& \mathrm{R} \quad=\text { Jari-jari hidrolis; yaitu A/P } \\
& \mathrm{S} \quad=\text { Kemiringan dasar saluan }
\end{aligned}
$$

\section{METODE}

\section{Lokasi penelitian}

Lokasi penelitian berada pada Jalan Harapan Kecamatan Rumbai Pesisir Kota Pekanbaru.

\section{Data Penelitian}

Pengumpulan data dari penelitian ini yaitu :

1. Pengumpulan data primer

Data primer yaitu data yang diambil langsung dari lokasi penelitian. Data yang digunakan untuk pengolaha data penelitian ini adalah :

- Data kondisi eksisting saluran drainase jalan harapan.

Data ini diambil langsung di lapangan dengan cara pengukuran. Data yang diambil yaitu dimensi saluran dan kedalaman sedimen. Dengan gambar seperti yang telampir pada lampiran.

- Data lebar dan panjang jalan harapan.

Data ini diambil langsung di lapagan dengan cara melakukan pengukuran. Data yang diambil adalah panjang jalan 1.800 meter dan lebar jalan 5 meter. Panjang jalan yang mengalami genangan yaitu 275 meter. 
- Data kontur

Data ini diambil langsung dengan melakukan pengukuran di lapangan.

- Data tata guna lahan

Data yang dibutuhkan untuk mengetahui jumlah debit buangan yang berada pada daerah sekitar saluran drainase. Data tata guna lahan di dapat langsung dari hasil survey lapangan pada tahun 2021.

2. Data sekunder

Data sekunder yaitu suatu data yang tidak diperoleh langsung dari lapangan dan bersifat mendukung data primer. Data yang di perlukan adalah :

- Data curah hujan yang di dapat dari Kantor BMKG Kota Pekanbaru.

- Data kependudukan.

\section{Analisis Data}

Pengolahan data penelitian ini dapat dilakukan dengan menggunakan rumus yang ada pada (SNI 03-3424-1994).

\section{HASIL DAN PEMBAHASAN}

Penelitian yang dilakukan adalah merencanakan saluran drainase pada Jalan Harapan Kecamatan Rumbai Pesisir Kota Pekanbaru. Berdasarkan perhitungan yang dilakukan di dapat data sebagai berikut :

1. Analisa frekuensi curah hujan

Data yang digunakan adalah data curah hujan pada daerah Kecamatan Rumbai Pesisir Kota Pekanbaru.

Tabel 1. Data Curah Hujan Tahunan Kecamatan Rumbai Pesisir

\begin{tabular}{c|c}
\hline \multicolumn{2}{c}{ Curah Hujan Kota Pekanbaru } \\
\hline Tahun & Curah Hujan $(\mathrm{mm})$ \\
\hline 2011 & 334 \\
\hline 2012 & 441 \\
\hline 2013 & 540 \\
\hline 2014 & 350 \\
\hline 2015 & 411 \\
\hline 2016 & 512 \\
\hline 2017 & 450 \\
\hline 2018 & 525 \\
\hline 2019 & 323 \\
\hline 2020 & 342 \\
\hline
\end{tabular}

(Sumber : BMKG Kota Pekanbaru, 2021) 
Miftahul Jannah, Virgo Trisep Haris, Muthia Anggraini / Jurnal Rab Contruction Research 6 (2) (2021)

Tabel 2. Perhitungan Curah Hujan Rata-Rata Dan Standar Devisai

\begin{tabular}{c|c|c|c}
\hline tahun & curah hujan rata-rata bulanan $(\mathrm{xi})$ & $(\mathrm{xi}-\mathrm{x})$ & $(\mathrm{xi}-\mathrm{x})^{\wedge} 2$ \\
\hline 2011 & 334 & $-88,8$ & 7885,44 \\
2012 & 441 & 18,2 & 331,24 \\
2013 & 540 & 117,2 & 13735,84 \\
2014 & 350 & $-72,8$ & 5299,84 \\
2015 & 411 & $-11,8$ & 139,24 \\
2016 & 512 & 89,2 & 7956,64 \\
2017 & 450 & 27,2 & 739,84 \\
2018 & 525 & 102,2 & 10444,84 \\
2019 & 323 & $-99,8$ & 9960,04 \\
2020 & 342 & $-80,8$ & 6528,64 \\
\hline Jumlah & 4228 & & 63021,6 \\
Rata-rata & 422,8 & & \\
\hline
\end{tabular}

Dari data diatas untun dapat menghitung nilai standar deviasi dengan menggunakan rumus (3).

$S x=\sqrt{\frac{\sum(x i-x)^{2}}{(n-1)}}$
$S x=\sqrt{\frac{63021,6}{(10-1)}}$

$S x=83,6803 \mathrm{~mm}$

Setelah di dapat nilai standar deviasi, lalu dilakukan perhitungan periode ulang 10 tahun dengan menggunakan rumus (3). Dengan nilai Sn sebesar 0,9496 dilihat pada Table (2.1). Nilai Yn sebesar 0,4952 dilihat pada Tabel (2.2) dan nilai Yt sebesar 2,2510 dilihat pada Table (2.3).

$$
\begin{aligned}
& X t=X r+\frac{S x}{S n}-(Y t-Y n) \\
& X t=422,8+\frac{83,6803}{0,9496}-(2,2510-0,4952) \\
& X t=509,1659 \mathrm{~mm}
\end{aligned}
$$

Dari hasil perhitungan yang dilakukan, diperoleh nilai $\mathrm{Xt}=509,1659 \mathrm{~mm}$ dan nilai $\mathrm{Sx}=$ $83,6803 \mathrm{~mm}$.

2. Analisa intensitas curah hujan

Analisa intensitas curah hujan dapat dihitung menggunakan rumus (3.5). 
$I=\frac{90 \% \times X T}{4}$

$I=\frac{90 \% \times 509,1659}{4}$

$I=114,5623 \mathrm{~mm} / \mathrm{jam}$

$I=0,0318 \mathrm{~mm} /$ detik

$I=0,00003182 \mathrm{~m} /$ detik

Dari hasil perhitungan yang telah dilakukan didapat intensitas curah hujan daerah Kecamatan Rumbai Pesisir 0,00003182 mm/det dan tergolong kategori sedang (100-300 $\mathrm{mm})$. Menurut BMKG, intensitas hujan tebagi menjadi kategori. Kategori rendah mulai daro (0-100 mm), kategori sedang mulai dari (100-300 mm), kategori tinggi mulai dari (300-500), dan kategori sangat tinggi $(>500 \mathrm{~mm})$. Semua kategori tersebut mempengaruhi terjadinya kekeringan.

3. Analisa Catchment area

Analisa catchmen area menggunakan ketentuan yang telah dikeluarkan (SNI 03-3424-1994). Perhitungan catchmen area untuk Jalan Harapan Kecamatan Rumbai Pesisir dengan panjang daerah aliran hulu hingga hilir saluran $674 \mathrm{~m}$, dapat dilihat pada Tabel 3.

Tabel 3. Luas Catchmen Area

\begin{tabular}{c|c|c|c}
\hline No & Keterangan & Jumlah $(\mathrm{m})$ & Jumlah $\left(\mathrm{m}^{2}\right)$ \\
\hline 1 & Permukaan Jalan (A1) & $674 \mathrm{~m} \times 5 \mathrm{~m}$ & 3370 \\
2 & Luas Pemukiman (A2) & $674 \mathrm{~m} \times 100 \mathrm{~m}$ & 67400 \\
3 & Luas Pemukiman (A3) & $674 \mathrm{~m} \times 100 \mathrm{~m}$ & 67400 \\
\hline & Luas Catchment area ( kanan dan kiri) & & 138170 \\
\hline
\end{tabular}

Dari perhitungan tabel 3. didapat luas catchmen area kiri dan kanan sebesar $138.170 \mathrm{~m}^{2}$.

4. Analisa koefisien aliran

Analisa koefisien pengaliran menggunakan ketentuan yang telah dikeluarkan SNI 03-34241994. Perhitungan koefisien pengaliran menggunakan rumus (6). berdasarkan tabel 2.4 didapat nilai C1 0,95 untuk permukaan jalan aspal. Nilai C3 sebesar 0,8 untuk pemukiman padat.

Koefisien pengaliran kiri.

$C=\frac{C 1 \cdot A 1+C 2 \cdot A 2}{A 1+A 2}$

$C=\frac{0,95.1 .685+0,8.69 .085}{1.685+69.085}$

$C=0,8036$

Koefisien sebelah kanan.

$C=\frac{C 1 \cdot A 1+C 2 \cdot A 2}{A 1+A 2}$ 
$C=\frac{0,95.1 \cdot 685+0,8.69 .085}{1.685+69.085}$

$C=0,8036$

Dari hasil perhitungan koefisien pengaliran di atas, nilai koefisien kiri dan kakan yang di dapat adalah 0,8036 .

5. Analisa deit curah hujan

Perhitungan analisa debit curah hujan dapat menggunakan rumus (7).

- Analisa debit hujan saluran kanan.

$$
\begin{aligned}
\text { Qch } & =0,278 \times \text { C } \times \text { I } \times \text { A } \\
& =0,278 \times 0,8036 \times 0,00003182 \times 69.085 \\
& =0,4911 \mathrm{~m}^{3} / \mathrm{det}
\end{aligned}
$$

- Analisa debit hujan saluran kanan.

$$
\begin{aligned}
\text { Qch } & =0,278 \times \mathrm{C} \times \mathrm{I} \times \mathrm{A} \\
& =0,278 \times 0,8036 \times 0,00003182 \times 69.085 \\
& =0,4911 \mathrm{~m}^{3} / \mathrm{det}
\end{aligned}
$$

Dari hasil perhitungan debit curah hujan yang dilakukan, debit curah hujan yang didapat sebesar $0,4911 \mathrm{~m}^{3} /$ det pada saluran kanan dan $0,4911 \mathrm{~m} 3 /$ det pada saluran kiri.

6. Analisa debit buangan

Pada perhitungan analisa debit buangan saluran drainase di bedakan menjadi bagian kiri dan bagian kanan.

- Saluran kanan

Pada saluran sebelah kanan terdapat beberapa bangunan yang terdiri dari 24 unit ruko, 183 unit rumah, dan 2 rumah ibadah. Perhitungan limbah buangan dapat dilakukan dengan rumus.

$$
\begin{array}{ll}
183 \text { unit rumah } & =183 \times 5 \text { org } \times 90 \mathrm{~L} / \text { hari } \\
& =82350 \mathrm{~L} / \text { hari/hari } \\
& =82,35 \mathrm{~m}^{3} / \mathrm{hari} \\
& =24 \times 1 \mathrm{~m}^{3} \\
& =24 \mathrm{~m}^{3} / \mathrm{hari} \\
2 \text { unit ruko } & =2 \times 3 \mathrm{~m}^{3} \\
\text { Total air buangan } & =6 \mathrm{~m}^{3} / \mathrm{hari} \\
& =82,35+24+6 \\
& =112,35 \mathrm{~m}^{3} / \mathrm{hari} \\
& =0,0013 \mathrm{~m}^{3} / \mathrm{det}
\end{array}
$$


Dari hasil perhitunggan debit buangan saluan kanan yang di lakukan, maka debit buangan saluran kanan yang didapat sebesar $0,0013 \mathrm{~m} 3 / \mathrm{det}$

- Saluran kiri

Pada saluran sebelah kanan terdapat bangunan, ruko 9 unit, rumah sebanyak 127 unit, dan rumah ibadah 1 unit. Perhitungan limbah buangan dapat di lakukan dengan rumus.

9 unit ruko $=9 \times 1 \mathrm{~m}^{3} / \mathrm{hari}$ $=9 \mathrm{~m}^{3} /$ hari

127 unit rumah

$$
=127 \times 5 \times 90 \mathrm{~L} / \mathrm{hari}
$$$$
=57150 \mathrm{~L} / \mathrm{hari}
$$$$
=57,15 \mathrm{~m}^{3} / \text { hari }
$$

1 unit rumah ibadah $\quad=1 \times 3 \mathrm{~m}^{3} / \mathrm{hari}$

$$
=3 \mathrm{~m}^{3} / \mathrm{hari}
$$

Total air buangan

$$
\begin{aligned}
& =9+57,15+3 \\
& =69,15 \mathrm{~m}^{3} / \text { hari } \\
& =0,0008 \mathrm{~m}^{3} / \text { det }
\end{aligned}
$$

Dari hasil perhitunggan debit buangan saluan kiri yang di lakukan, maka debit buangan

\begin{tabular}{|c|c|c|c|c|c|c|c|c|c|}
\hline Kedalaman & Lebar & Elevas & Saluran & \multicolumn{6}{|c|}{ Kapasitas Saluran Drainase } \\
\hline Saluran & Saluran & & $\mathrm{T} 2$ & A & $\mathrm{P}$ & $\mathrm{R}$ & $\mathrm{S}$ & Vmanning & Q \\
\hline $\begin{array}{c}\text { Rencana }(\mathrm{H}) \\
(\mathrm{m})\end{array}$ & (B) $(\mathrm{m})$ & $\mathrm{T} 1$ & & & & & & & \\
\hline 1,300 & 1,1 & 99,338 & 99,317 & 1,43 & 3,7 & 0,386 & 0,0008 & 1,025 & 1,466 \\
\hline
\end{tabular}
saluran kiri yang didapat sebesar $0,0008 \mathrm{~m}^{3} / \mathrm{det}$

7. Analisa kiriman

- Perhitungan debit kiriman saluran kanan

Tabel 4 Perhitungan Debit Kiriman Saluran Drainase Kiri

\begin{tabular}{|c|c|c|c|c|c|c|c|c|}
\hline Kedalaman & Lebar & Elevasi & \multicolumn{6}{|c|}{ Kapasitas Saluran Drainase } \\
\hline Rencana $(\mathrm{H})$ & $\mathrm{n}(\mathrm{B})$ & $\mathrm{T} 2$ & A & $\mathrm{P}$ & $\mathrm{R}$ & $\mathrm{S}$ & Vmanning & Q \\
\hline (m) & (m) & $\mathrm{T} 1$ & & & & & & \\
\hline
\end{tabular}

Jadi nilai Q (Debit eksisting) saluran drainase sebelah kanan yang didapat adalah sebesar $1,446 \mathrm{~m}^{3} /$ det.

- Perhitungan debit kiriman sebelah kanan

Tabel 5 Perhitungan Debit Kiriman Saluran Drainase Kanan 


$\begin{array}{llllllllll}1,700 & 1,75 & 98,529 & 98,518 & 2,975 & 5,15 & 0,578 & 0,0004 & 0,970 & 2,886\end{array}$

Jadi nilai Q (Debit eksisting) saluran drainase sebelah kanan yang didapat adalah sebesar $2,8856 \mathrm{~m}^{3} /$ det.

8. Analisa debit rencana

Analisa debit rencana dapat dilakukan dengan menggunakan rumus (3.9).

- Debit saluran kanan

$$
\begin{aligned}
\text { Qr } & =\text { Qch }+ \text { Qak }+ \text { Qk } \\
& =0,4911+0,0013+2,886 \\
& =3,3781 \mathrm{~m}^{3} / \mathrm{det}
\end{aligned}
$$

- Debit saluran kiri

$$
\begin{aligned}
\text { Qr } & =Q c h+\text { Qak }+ \text { Qk } \\
& =0,4911+0,0008+1,466 \\
& =1,9579 \mathrm{~m}^{3} / \mathrm{det}
\end{aligned}
$$

Berdasarkan hasil perhitungan debit total pada saluran drainase, sehingga debit saluran drainase sebelah kanan sebesar 3,3781 $\mathrm{m}^{3} /$ detik dan debit saluran drainase sebelah kiri sebesar $1,9579 \mathrm{~m}^{3} /$ det.

9. Perencanaan ulang salran drainase

Dari perhitungan yang telah dilakukan, dapat diketahui debit total dari saluran kiri dan kanan yang akan digunakan pada perencanaan saluran drainase sebagai berikut :

Data perencanaan :

Perencanaan saluran kanan

- Bentuk saluran

$$
\begin{aligned}
& =\text { Persegi } \\
& =674 \mathrm{~m} \\
& =3,3781 \mathrm{~m} 3 / \mathrm{det} \\
& =1,5 \mathrm{~m} / \mathrm{det} \\
& =0,0003 \\
& =99,013
\end{aligned}
$$

- Panjang saluran

- Debit saluran (Q)

- Kecepatan aliran (V)

- Kemiringan rencana (S)

- Elevasi hulu saluran (t1)

$$
\begin{array}{ll}
\text { kemiringan rencana } & =\frac{\text { elevasi hulu }(t 1)-\text { elevasi hilir }(t 2)}{\text { panjang saluran }} \\
0,0003 & =\frac{99,013-t 2}{674} \\
99,013-\mathrm{t} 2 & =0,0003 \times 674 \\
99,013-0,2022 & =\mathrm{t} 2 \\
98,8108 & =\mathrm{t} 2
\end{array}
$$


Perencanaan dimensi saluran drainase bentuk persegi dapat dilakukan dengan menggunakan rumus (3.14) :

$Q=A x V$

$A=\frac{Q}{V}=\frac{3,3781 \mathrm{~m}^{3} / \text { det }}{1,5 \mathrm{~m} / \text { det }}=2,2521 \mathrm{~m}^{2}$

$A=B^{2}$

$B=\sqrt{A}$

$B=\sqrt{2,2521}$

$B=1,5006 m \approx 1,5 m$

Setelah dilakukan perhitungan dimensi saluran, dimensi saluran efektif yang di dapat adalah tinggi $1,5 \mathrm{~m}$ x lebar $1,5 \mathrm{~m}$. Berdasarkan debit yang di dapat pada saat perhitungan debit rencana saluran, tinggi jagaan saluran yang di dapat adalah $0,25 \mathrm{~m}$, sehingga dimensi saluran menjadi $1,75 \mathrm{~m} \times 1,5 \mathrm{~m}$.

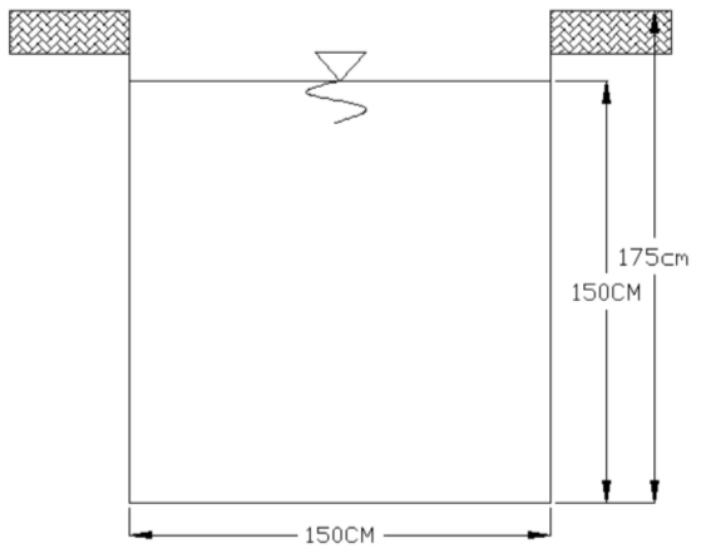

Gambar 2. Dimensi Saluran Kanan Rencana

Perencanaan saluran kiri :

- Bentuk saluran

$=$ Persegi

- Panjang saluran

$=674 \mathrm{~m}$

- Debit saluran (Q)

$=1,9579 \mathrm{~m}^{3} / \mathrm{det}$

- Kecepatan aliran (V)

$=1,5 \mathrm{~m} / \mathrm{det}$

- Kemiringan rencana (S)

$=0,0003$

- Elevasi hulu saluran (t1)

$=98,429$

kemiringan rencana $=\frac{\text { elevasi hulu }(t 1)-\text { elevasi hilir }(t 2)}{\text { panjang saluran }}$ 


$$
\begin{array}{ll}
0,0003 & =\frac{98,429-t 2}{674} \\
98,429-\mathrm{t} 2 & =0,0003 \times 674 \\
98,429-0,2022 & =\mathrm{t} 2 \\
98,2268 & =\mathrm{t} 2
\end{array}
$$

Perencanaan dimensi saluran drainase bentuk persegi dapat dilakukan dengan menggunakan rumus (3.14) :

$Q=A \times V$

$A=\frac{Q}{V}=\frac{1,9579 \mathrm{~m}^{3} / \text { det }}{1,5 \mathrm{~m} / \text { det }}=1,3053 \mathrm{~m}^{2}$

$A=B^{2}$

$B=\sqrt{A}$

$B=\sqrt{1,3053}$

$B=1,1425 m \approx 1,2 m$

Setelah dilakukan perhitungan dimensi saluran, dimensi saluran efektif yang di dapat adalah tinggi 1,2 $\mathrm{m} \times$ lebar 1,2 m. Berdasarkan debit yang di dapat pada saat perhitungan debit rencana saluran, tinggi jagaan saluran yang di dapat adalah $0,25 \mathrm{~m}$, sehingga dimensi saluran menjadi $1,45 \mathrm{~m} \times 1,2 \mathrm{~m}$.

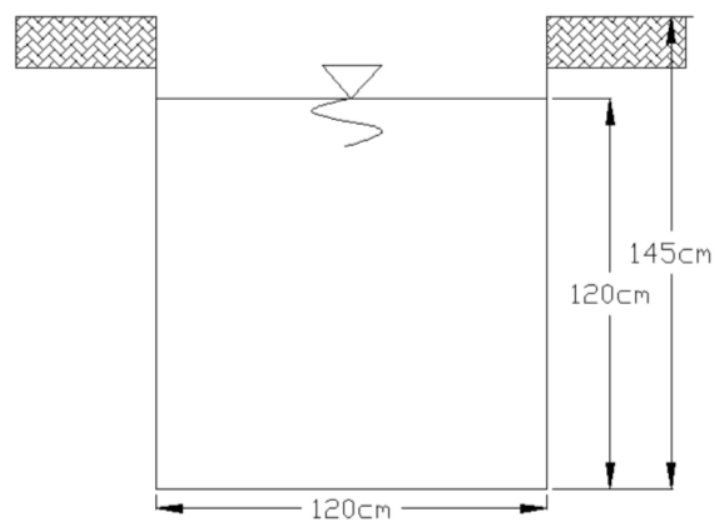

Gambar 3. Dimensi Saluran Kiri Rencana

\section{SIMPULAN}

Hasil penelitian yang telah dilakuakn sehingga didapat kesimpulan bahwa dimensi saluran rencana pada saluran kanan dengan tinggi 1,75 meter dan lebar 1,5 meter, dimensi saluran kiri dengan tinggi 1,45 meter dan lebar 1,2 meter.

\section{UCAPAN TERIMA KASIH}


Ucapan terima kasih penulis sampaikan kepada pembimbing I dan pembimbing II yang telah bersedia membimbing dan mengarahkan serta memberi masukan dan saran kepada penulis sehingga penelitian yang dilakukan dapat berjalan dengan baik.

\section{DAFTAR PUSTAKA}

[1] D. A. D. Nusantara, "Evaluasi Kapasitas Saluran Drainase di Catchment Area Sub Sistem Bendul Merisi Kota Surabaya," UKaRsT, vol. 4, no. 1, p. 84, 2020, doi: 10.30737/ukarst.v4i1.689.

[2] A. K. Dewi, A. Setiawan, and A. P. Saido, "Evaluasi Sistem Saluran Drainase di Ruas Jalan Solo Sragen Kabupaten Karanganyar," J. Matriks Tek. Sipil, vol. 2, no. 1, pp. 170-176, 2014.

[3] Suripin, Sistem Drainase Perkotaan Yang Berkelanjutan. Yogyakarta: Andi, 2004.

[4] H. A. H. Hasmar, Drainase terapan. yogjakarta, 2012.

[5] N. K. S. Kartika, I. W. Muliawan, and A. A. S. D. Rahadiani, "Evaluasi Fungsi Saluran Drainase Terhadap Kondisi Jalan Gunung Rinjani Di Wilayah Kecamatan Denpasar Barat," WICAKSANA J. Lingkung. dan Pembang., vol. 2, no. 1, pp. 17-24, 2018.

[6] H. Hasmar, Drainasi Terapan. Yogyakarta: UII Press, Yogyakarta, 2002.

[7] B. Andana, D. Arisanty, and S. Adyatma, "Evaluasi Daya Tampung Sistem Drainase Di Kecamatan Banjarmasin Selatan," JPG (Jurnal Pendidik. Geogr., vol. 3, no. 4, pp. 1-13, 2016.

[8] D. Fairizi, "Analisis dan Evaluasi Saluran Drainase Pada Kawasan Perumnas Talang Kelapa Di Subdas Lambidaro Kota Palembang,” Sipil, Jur. Tek. Sriwijaya, Univ. Besar, Bukit Sumatera, Palembang, vol. 3, no. No. 1, 2015.

[9] SNI 03-3424:1994, “Tata Cara Perencanaan Drainase Permukaan Jalan,” 1994, p. 3424.

[10] F. Gunawan, V. T. Haris, and M. Anggraini, "Perencanaan Drainase Pada Jalan Umban Sari Disepanjang STA $0+500$ Hingga STA $0+750$ Kecamatan Rumbai Kota Pekanbaru," $J$. Tek., vol. 14, pp. 178-187, 2020.

[11] A. N. Jifa, L. D. Susanaati, and A. T. S. Haji, "Evaluasi Saluran Drainase di Jalan Gajayana dan Jalan Sumbersari Kota Malang,” J. Sumberd. Alam dan Lingkung., pp. 9-17. 